\title{
The Use of Somatostatin Receptor Scintigraphy in the Differential Diagnosis of Pancreatic Duct Cancers and Islet Cell Tumors
}

\author{
Casper H. J. van Eijck, M.D., Ph.D., ${ }^{\star}$ Steven W. J. Lamberts, M.D., Ph.D., $†$ \\ Luciene C. J. M. Lemaire, M.D., ${ }^{*}$ Hans Jeekel, M.D., Ph.D., ${ }^{*} F r e$ T. Bosman, M.D., Ph.D., \\ Jean-Claude Reubi, M.D.,Ph.D.,§ Hajo A. Bruining, M.D., Ph.D., * \\ and Eric P. Krenning, M.D., Ph.D.\|
}

From the Departments of Surgery, * Internal Medicine III, † Pathology, $\ddagger$ and Nuclear Medicine, $\|$ University Hospital, Rotterdam, The Netherlands; and the Department of Pathology, $§$ University of Berne, Berne, Switzerland

\section{Objective}

In the present study, the diagnostic value of somatostatin receptor scintigraphy (SRS) was evaluated in the preoperative workup in patients with pancreatic duct cancers and islet cell tumors, as well as in the follow-up of these patients.

\section{Methods}

Twenty-six patients with suspected primary pancreatic duct cancers and 48 patients with islet cell tumors were studied. The SRS was performed using the radionuclide-labeled somatostatin analogue ${ }^{111}$ In-octreotide. Another group of 12 patients who were still alive more than 3 years after pancreaticoduodenectomy for pancreatic duct adenocarcinomas also underwent SRS.

\section{Results}

In $31(65 \%)$ of 48 patients, the primary pancreatic islet cell tumor as well as its often previously not yet recognized metastases could be visualized. In contrast, none of the 26 pancreatic adenocarcinomas or their metastases could be seen. In 5 of 12 patients who were alive more than 3 years after pancreaticoduodenectomy for pancreatic duct adenocarcinomas, metastatic lesions were visualized at SRS. In retrospect, these patients were not operated on for adenocarcinomas but for "nonfunctioning" islet cell tumors.

\section{Conclusions}

The present study supports the concept that SRS has a place in the preoperative differential diagnosis of islet cell tumors and pancreatic duct cancers as well as in the follow-up, especially in those cases in which no tumor histologic analysis was obtained, or the pathologic examination of the tumor tissue had not included special staining procedures for neuroendocrine characteristics. Our results also indicate that the evaluation of the results of investigations on the role of surgery or radiation therapy and chemotherapy or both in pancreatic duct cancer have to be interpreted with caution, if no histologic analysis and staining for neuroendocrine characteristics was performed. 
Somatostatin receptors (SS-Rs) have been found on a variety of neuroendocrine tumors like carcinoids, paragangliomas, as well as on brain tumors, such as meningiomas. ${ }^{1-3}$ The SS-Rs also are present on most pancreatic islet cell tumors, ${ }^{4,5}$ whereas previous in $v i$ tro studies indicate the absence of these receptors on pancreatic duct cancers. ${ }^{6}$

Endocrine pancreatic tumors or islet cell tumors constitute a small, but important, group of pancreatic tumors. The annual incidence of islet cell tumors was found to be 0.4 per 100.000 population. ${ }^{7}$ Most of these tumors produce multiple hormones, but usually excessive secretion of one hormone predominates, causing specific clinical symptomatology ${ }^{8.9}$ However, approximately $15 \%$ to $40 \%$ of islet cell tumors do not give rise to hormone-related symptoms and are therefore called "nonfunctioning." 10,11 The reasons why they are clinically silent include the absence of the release hormones, the production of biologically inactive prohormones, the production of hormones that do not cause clinical symptoms (e.g., pancreatic polypeptide, chromogranin A), and downregulation of hormone receptors or the production of inhibitory hormones, such as somatostatin, or both. ${ }^{12}$ Most patients with nonfunctioning islet cell tumors have rather uncharacteristic symptoms at presentation. The correct diagnosis is therefore made at a late stage when extensive tumor growth has occurred. ${ }^{7,13,14}$ In general, islet cell tumors grow slowly, but the significantly shorter survival of patients with nonfunctioning islet cell tumors compared with those that cause signs and symptoms of hormonal secretion indicates a more malignant behavior of this subtype. ${ }^{7}$ However, this also might be because these tumors are diagnosed later. In $70 \%$ to $80 \%$ of the cases, liver metastases are present at the time of diagnosis in patients with nonfunctioning islet cell tumors.

Preoperative differentiation between pancreatic duct carcinomas and islet cell tumors is of importance, because palliative surgery in patients with islet cell tumors is not only of value to relieve clinical symptoms but also to decrease the tumor burden, which might enhance the effect of medical treatment. ${ }^{15}$

Recently we introduced a new nuclear medical technique in which SS-R-positive tumors could be visualized in vivo after the administration of a radionuclide-labeled somatostatin analogue followed by gamma-camera scintigraphy. ${ }^{16-20}$ In the present study, we investigated the diagnostic value of this technique in the workup of patients with pancreatic endocrine and exocrine tumors. The results of this in vivo technique were correlated with

Address reprint requests to Casper H. J. van Eijck, M.D., Ph.D., Department of Surgical Oncology, University Hospital Dijkzigt, Dr. Molewaterplein 40, 3015 GD, Rotterdam, The Netherlands. Accepted for publication August 15, 1995. the results of in vitro receptor autoradiographic studies in tumor specimen.

\section{PATIENTS AND METHODS}

\section{Patients Selection}

Twenty-six patients with primary pancreatic duct cancers (mean age, 64 years; range, 42-81) were studied. After clinical and laboratory investigations searching for a primary tumor in the pancreas, all patients underwent ultrasonography, computed tomography (CT) scanning, and endoscopic retrograde cholangiopancreatography. Whenever possible, cytologic analysis of the tumor was obtained. After informed consent was obtained from the patient to participate in this study, somatostatin receptor scintigraphy (SRS) was performed after bowel preparation on an outpatient basis. Without surgeons' taking into consideration the scintigraphic results, 22 patients were subsequently operated on for suspected pancreatic duct carcinoma. Four patients were not operated on because of cytologically proven metastatic disease.

Tumor tissue specimens from these 22 patients who were operated on were stained with hematoxylin and eosin and examined for homogeneous cell structure and characteristic growth patterns of exocrine and endocrine tumors. The Grimelius silver staining technique was used, as well as immunocytochemical staining with antisera against neuron-specific enolase and chromogranin A to confirm a possible endocrine nature of the tumor. In addition, immunocytochemical staining with antisera against insulin, gastrin, pancreatic polypeptide, vasoactive intestinal polypeptide, somatostatin, glucagon, and neurotensin was performed. Tumors were histologically classified by one pathologist, who was not informed about the SRS results. Whenever enough tumor tissue was available, the presence of SS-Rs was studied by in vitro autoradiographic analysis on cryostat sections, as has been described previously. ${ }^{4}$

Another group of 12 patients who were still alive more than 3 years after subtotal $(n=10)$ or total $(n=2)$ pancreaticoduodenectomy performed for pancreatic duct adenocarcinomas also underwent an SRS. Five of these patients were known to have metastatic disease when SRS was performed. Revision of the tumor blocks of these patients that had been previously reviewed by other pathologists took place as described above. No more autoradiographic analysis could be done on these tumor specimens.

The results of the scintigraphy of the patients described above where compared with the results obtained in 48 patients with endocrine pancreatic tumors. Part of the results obtained in 25 individuals have been described previously. ${ }^{21}$ 

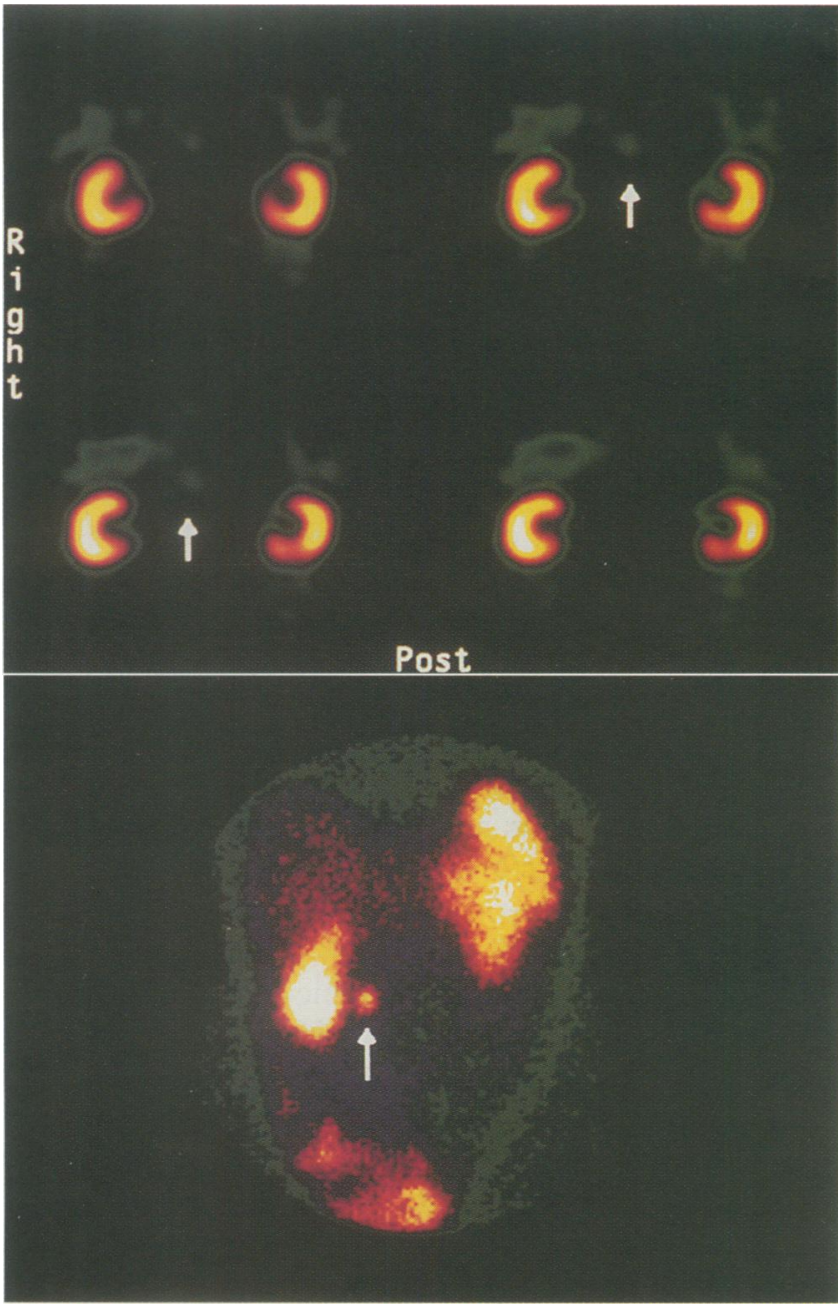

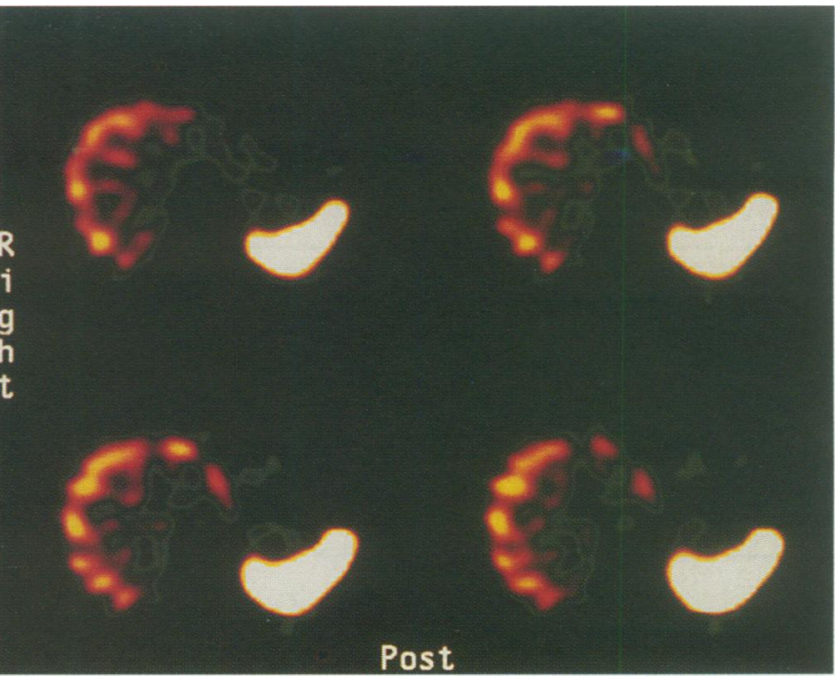

Figure 1. Top left. Twenty-four hour transversal single photon emission computed tomography abdominal [11'In-DTPA-D-Phe ${ }^{1}$ ]-octreotide scintigram of a patient with a "nonfunctioning" islet cell tumor showing a hot spot at the side of the primary tumor in the caput of the pancreas (arrow) between the kidneys. Top right. Many hot spots (yellow) in the liver representing metastases (spleen in white). These metastases could not be visualized by ultrasound or computed tomography scan.

Figure 2. Left. [ ${ }^{11}{ }^{1}$ In-DTPA-D-Phe']-octreotide scan of a $1.5-\mathrm{cm}$ insulinoma in the head of the pancreas (arrow). Anterior view of the abdomen obtained at 24 hours.

\section{Material}

The somatostatin analogue [DTPA-D-Phe ${ }^{1}$ ]-octreotide (Mallinckrodt Medical BV, Petten, The Netherlands) was labeled with "ultra-pure" Indium 111 ([ $\left.{ }^{111} \mathrm{In}\right]$, Mallinckrodt Medical BV, Petten, The Netherlands). The labeling procedure has been described elsewhere. ${ }^{22}$ Doses ranged from $222 \mathrm{MBq}$ to $272 \mathrm{MBq}\left[{ }^{111} \mathrm{In}\right.$-DTPAD-Phe ${ }^{1}$-octreotide.

\section{Scintigraphy}

After bowel preparation ( $2 \mathrm{~L}$ polyethyleneglycol), planar and, in most patients, also single photon emission computed tomography images were obtained as described previously. ${ }^{20,23}$

\section{RESULTS}

[ ${ }^{111}$ In-DTPA-Phe $\left.{ }^{1}\right]$-octreotide scintigraphy (SRS) was carried out before operation in 26 patients with suspected pancreatic duct carcinomas. None of these tu- mors or their metastases could be visualized. Twelve patients were subsequently treated by a Whipple procedure, 2 by total pancreatectomy, 2 patients by a palliative procedure (gastroenterostomy or choledochoduodenostomy or both) after transduodenal biopsy was performed, and 6 patients had a biopsy only. Four patients were not operated on because cytologic analysis of suspected lesions in the liver showed adenocarcinoma. Pancreatic duct carcinoma was found in 18 patients who were operated on. None of these tumors showed neuroendocrine characteristics. In 16 of these tumors, autoradiographic studies of the surgically removed tumor tissue could be done and no SS-Rs were present. In two patients, the tumor was so extensive that no resection could be done. Transduodenal biopsies in these two patients, however, showed atypia without any evidence of infiltrating tumor cells, which must be considered a sampling error. The other two patients underwent a Whipple procedure for chronic pancreatitis. In these patients also, no abnormalities were detected at SRS. No autoradiographic analysis was done on the tissue of these patients. 
Table 1. INCIDENCE OF SOMATOSTATIN

RECEPTORS ON ENDOCRINE PANCREATIC TUMORS IN VIVO AND IN VITRO AS DEMONSTRATED BY SCINTIGRAPHY AND AUTORADIOGRAPHY

\begin{tabular}{lcc}
\hline & In Vivo & In Vitro \\
\hline Vipomas & $1 / 1$ & $1 / 1$ \\
Gastrinomas & $13 / 14$ & $10 / 11$ \\
Glucagonomas & $1 / 1$ & $1 / 1$ \\
Insulinomas & $13 / 28$ & $8 / 11$ \\
"Nonfunctioning" islet cell tumors & $2 / 2$ & $2 / 2$ \\
Somatostinomas & $1 / 2$ & - \\
\hline
\end{tabular}

Because long-term survival of patients with pancreatic duct carcinoma is rare, we looked in retrospect at our group of long-term survivors after surgery for pancreatic duct carcinomas. Long-term survivors were defined as patients who lived more than 3 years after the primary operation. Of 62 patients who had been operated on between 1985 and 1990, 12 patients were found to be alive for 3 or more years. Five of these 12 patients were known to have metastases. These 12 patients underwent SRS. In seven patients, no abnormalities were seen, whereas other investigations also suggested that these patients were tumor free at that moment. However, in five "survivors" in whom the presence of metastases was known, all metastatic lesions as well as a number of additional tumor sites were visualized at SRS. Examples of the scintigram obtained in one of these patients are shown in Figure 1.

Revision of the original tumor blocks, including the additional staining procedures mentioned above, showed that these five patients in retrospect were operated on primarily for nonfunctioning islet cell tumors. In the group of seven patients without known metastases and without abnormalities at SRS, revision of the pathologic analysis confirmed that these patients indeed had been cured from pancreatic duct cancer.

Table 1 lists the results of in vivo scintigraphy of a group of 48 patients with different islet cell tumors. Twenty-one of the tumors have been investigated both in vitro and in vivo. In all cases, the results in vitro and in vivo investigations were parallel.

The application of SS-R imaging proved to be highly successful. The primary endocrine pancreatic tumors as well as their often previously not yet recognized metastases could be visualized in 31 (65\%) of these 48 patients. Metastases were actually scintigraphically evident in 13 patients. Twenty-six of these patients subsequently were operated on in our hospital, allowing surgical evaluation of the scintigraphic results. In one patient with gastrinoma, no lymph node metastasis on the aortic arch was found at operation, despite it being suggested at CT scanning. In another pa- tient with gastrinoma who had familial multiple endocrine adenomatosis type I, the scintigraphically detected tumor was indeed found in the tail of the pancreas, but during operation, an additional islet cell tumor was found in the corpus of the pancreas. This tumor had not been seen on SRS. Unfortunately, no somatostatin autoradiographic analysis of this tumor was done.

The visualization of insulinomas with this technique proved to be more difficult. We localized the tumors with SRS in only 13 of 28 patients investigated to date. In vitro autoradiographic analysis showed that all insulinomas contained receptors for somatostatin-14 and somatostatin-28, but that octreotide receptors were absent on the tumors, which could not be visualized in vivo. An example of the gamma picture obtained in one patient with an insulinoma is shown in Figure 2.

\section{DISCUSSION}

After Schönbrunn and Tashjian first measured SS-Rs in 1978 using the clonal pituitary cell line GH4C, ${ }^{24}$ SSRs have been shown on a variety of human tumors, using various iodinated SS analogues in homogenate ligandbinding assays or autoradiographic analysis on tissue sections. ${ }^{25,26}$ Large numbers of binding sites with high affinity for SS were found on most tumors with amine precursor uptake and decarboxylation (APUD) characteristics, as well as on meningiomas, well-differentiated brain tumors (astrocytomas), neuroblastomas, and human breast tumors. ${ }^{27-43}$ Examples of tumors with amine precursor uptake and decarboxylation characteristics that are often SS-R-positive are growth-hormone-producing pituitary adenomas, endocrine pancreatic tumors, carcinoids, paragangliomas, small cell lung cancers, medullary thyroid carcinomas, and pheochromocytomas. Recently, at least five different human SS-R subtypes have been cloned. ${ }^{44-48}$ Octreotide binds with high affinity to subtype $2\left(\right.$ SSTR $\left._{2}\right)$, whereas this analogue has a relatively low affinity to $\mathrm{SSTR}_{3}$ and $\mathrm{SSTR}_{5}$ and shows no binding to subtypes 1 and 4 (SSTR $_{1}$ and SSTR $_{4}$ ). The majority of the receptor-positive human tumors expressed the SS- $\mathrm{R}_{2}$ subtype, whereas only a minority of tumors had exclusively other SS-R subtypes. ${ }^{47}$

For the visualization of SS-R-positive tumors, we used a radionuclide-labeled somatostatin analogue, [ ${ }^{111}$ InDTPA-D-Phe ${ }^{1}$ ]-octreotide, because there are several arguments that octreotide scintigraphy represents SS-R imaging. Pretreatment with high doses of unlabeled octreotide prevents tumor uptake of ${ }^{111}$ In-DTPA-D$\mathrm{Phe}^{1}$ ]-octreotide in rats bearing SS-R-positive tumors. ${ }^{22}$ Autoradiographically, it also was found that only the anterior lobe of the rat pituitary, which is the only part of this organ with SS-Rs, showed specific binding of the radioligand after its injection. ${ }^{49}$ As has been found in our study as well, a close relation exists between the presence 
of SS-Rs, showed with in vitro autoradiographic analysis, and the visualization of tumors and diseases by in vivo octreotide scintigraphy.

There are many promising reports on the potential benefit of radiolabeled monoclonal antibodies for in vivo tumor detection. However, their widespread application has been hampered for several reasons. The low tumor-tobackground ratios achieved with this technique is because of the large molecules often used, which lead to a high background radioactivity. Because of the rapid clearance of the small-sized [ ${ }^{111}$ In-DTPA-D-Phe ${ }^{1}$ ]-octreotide by the kidneys, a much higher tumor-to-background ratio can be obtained. Antibody formation, which often can be found after administration of monoclonal antibodies, is extremely rare in patients treated with octreotide. Therefore, the SS-R imaging can be repeated easily without any risk of an anaphylactic reaction.

Generally, patients with pancreatic islet cell tumors have a better prognosis than those with exocrine, mostly ductal adenocarcinomas. ${ }^{50}$ However, despite improvements in diagnostic methods, the median delay between the appearance of the first symptoms and the diagnosis has not been reduced, and most patients are encountered when the tumor has reached an advanced stage. ${ }^{8.13,14}$ As pointed out by Eriksson et al., ${ }^{7}$ there is a need for optimalization of screening patients with uncharacteristic abdominal symptoms for the presence of islet cell tumors. In addition to the measurements of plasma levels of chromogranin A and pancreatic hormones, SS-R scintigraphy can be used to show the presence of such tumors.

In this study, the sensitivity of the SS-R scintigraphy in localizing islet cell tumors was high, except in the case of insulinomas. The presence of other subtypes of SS-Rs in this tumor is well known. Only approximately $60 \%$ of the insulinomas express the $\mathrm{SSTR}_{2}$ subtype, and this necessitates the development of other radionuclide-labeled somatostatin analogues that recognize other subtypes of the SS-R. Other factors that generally may interfere with the visualization of neuroendocrine tumors include the presence of unlabeled somatostatin (e.g., by autocrine, paracrine, or endocrine production of somatostatin or somatostatin analogue administration). In both cases, this may result in receptor blockade or "down" regulation of the receptor.

Finally, the difference in SS-R expression between islet cell tumors and pancreatic duct cancers seems to offer the possibility to differentiate between these tumors before operation. This is important, because palliative surgery in patients with islet cell tumors is not only of value to relieve clinical symptoms but also to decrease tumor burden, which might enhance the effect of medical treatment, resulting in a better clinical condition and a longer survival. ${ }^{15}$ The use of SS-R scintigraphy as a diagnostic technique for suspected islet cell tumors is favored because of its harmless, noninvasive nature. In islet cell tu- mors, ultrasound and CT are usually limited to the pancreas and liver region, thereby missing possible extra-abdominal metastases. Further studies comparing intraoperative ultrasound, surgical palpation, and guided surgery using a hand-held radionuclide-detecting probe after the administration of [ ${ }^{11}$ In-DTPA-D$\left.\mathrm{Phe}^{1}\right]$-octreotide are necessary to determine the best method to localize the endocrine tumor before operation. Therefore, the SS-R scintigraphy should be performed to see if the tumor contains SS-Rs, to support diagnosis of an islet cell tumor, and to stage the patient directly.

The present study supports the concept that SRS may have a place in the preoperative differential diagnosis of endocrine pancreatic tumors, especially nonfunctioning islet cell tumors, and pancreatic ductal cancers, as well as in the follow-up, especially in those cases in which the pathologic examination of the tumor tissue had not included special staining procedures for neuroendocrine characteristics. Our results also indicate that the evaluation of the investigative results on the role of surgery or radiation therapy and chemotherapy or both in pancreatic duct cancer have to be interpreted with caution, if no histologic analysis and staining for neuroendocrine characteristics were performed.

\section{References}

1. Reubi JC, Kvols LK, Krenning EP, Lamberts SWJ. Distribution of somatostatin receptors in normal and tumor tissue. Metabolism $1990 ; 39: 78-81$.

2. Reubi JC, Cortes R, Maurer R, et al. Distribution of somatostatin receptors in the human brain: an autoradiographic study. Neuroscience $1986 ; 18: 329-346$.

3. Reubi JC, Lang W, Maurer R, et al. Distribution and biochemical characterization of somatostatin receptors in tumors of the human central nervous system. Cancer Res 1987; 47:5758-5764.

4. Reubi JC, Häcki WH, Lamberts SWJ. Hormone-producing gastrointestinal tumors contain high density of somatostatin receptors. J Clin Endocrinol Metab 1987; 65:1127-1134.

5. Reubi JC, Maurer R, von Werder K, et al. Somatostatin receptors in human endocrine tumors. Cancer Res 1987; 47:551-558.

6. Reubi JC, Horisberger U, Essed CE, et al. Absence of somatostatin receptors in human exocrine pancreatic adenocarcinomas. Gastroenterology 1988; 95:760-763.

7. Eriksson B. Recent advances in the diagnosis and management of endocrine pancreatic tumors. Acta Universitatis Upsaliensis 1988; 160. Thesis.

8. Eriksson B, Arnberg H, Lindgren PG, et al. Neuroendocrine pancreatic tumours: clinical presentation, biochemical and histopathological findings in 84 patients. J Intern Med 1990; 228:103-113.

9. Bloom SR, Polak JM. Glucagonomas, VIPomas and somatostinomas. Clin Endocrinol Metab 1980; 9:285-297.

10. Solcia E, Sessa F, Rindi G, et al. Pancreatic endocrine tumors: general concept; nonfunctioning tumors and tumors with uncommon function. In Dayal Y, ed. Endocrine Pathology of the Gut and Pancreas. Boston: CRC Press; 1991:105-131.

11. Kloppel G, Heitz PU. Pancreatic endocrine tumors. Pathol Res Pract 1988; 183:155-168.

12. Öberg K, Eriksson B, Lundqvist M. Neuroendocrine tumours of 
the upper gastrointestinal tract and pancreas. Acta Chirurgica Scandinavica Supplementum 1988; 541:76-85.

13. Kent RB, van Heerden JA, Weiland LH. Nonfunctioning islet cell tumors. Ann Surg 1981; 193:185-190.

14. Marchal G, Seguin C. Les tumeurs endocrines du pancreas. Lyon Chir 1980; 76:217-221.

15. Norton JA, Sugarbaker PH, Doppman JL, et al. Aggressive resection of metastatic disease in selected patients with malignant gastrinoma. Ann Surg 1986; 203:352-359.

16. Krenning EP, Bakker WH, Breeman WA, et al. Localization of endocrine related tumors with radioiodinated analog of somatostatin: Lancet 1989; i:242-245.

17. Lamberts SWJ, Bakker WH, Reubi JC, Krenning EP. Treatment with sandostatin and in vivo localization of tumors with radiolabeled somatostatin analog. Metabolism 1990; 39:152-155.

18. Lamberts SWJ, Hofland LJ, van Koetsveld PH, et al. Parallel in vivo and in vitro detection of functional somatostatin receptors in human endocrine pancreatic tumors: consequences with regards to diagnosis, localization and therapy. J Clin Endocrinol Metab 1990; 71:566-574.

19. Lamberts SWJ, Bakker WH, Reubi JC, Krenning EP. Somatostatin receptor imaging in the localization of endocrine tumors. $\mathrm{N}$ Engl J Med 1990; 323:1246-1249.

20. Krenning EP, Kwekkeboom DJ, Bakker WH, et al. Somatostatin receptor scintigraphy with [ ${ }^{111}$ In-DTPA-D-Phe $\left.{ }^{1}\right]-$ and $\left[{ }^{123} \mathrm{I}-\mathrm{Tyr}{ }^{3}\right]$ octreotide: the Rotterdam experience with more than 1000 patients. Eur J Nucl Med 1993; 20:716-731.

21. van Eyck CHJ, Bruining HA, Reubi JC, et al. Use of isotope-labeled somatostatin analogs for visualization of islet cell tumors. World J Surg 1993; 17:444-7.

22. Bakker WH, Albert R, Bruns C, et al. [ ${ }^{111}$ In-DTPA-D-Phe']-octreotide, a potential radiopharmaceutical for imaging of somatostatin receptor-positive tumors: synthesis, radiolabeling and in vitro validation. Life Sci 1991; 49:1583-1591.

23. Krenning EP, Kwekkeboom DJ, Bakker WH, et al. Somatostatin receptor scintigraphy with [ ${ }^{111}$-DTPA-d-Phe $\left.{ }^{1}\right]$-and $\left[{ }^{123}-\mathrm{Tyr}^{3}\right]$-octreotide; the Rotterdam experience with more than 1000 patients. Eur J Nucl Med 8:715-731.

24. Schönbrunn A, Tashjian A. Characterization of functional receptors for somatostatinin rat pituitary cells in culture. J Biol Chem 1978; 253:6473-6483.

25. Reubi JC, Kvols LK, Krenning EP, Lamberts SWJ. Distribution of somatostatin receptors in normal and tumor tissue. Metabolism 1990; 39:78-81.

26. Reubi JC, Krenning EP, Lamberts SWJ, Kvols LK. Somatostatin receptors in malignant tissues. J Steroid Biochem Mol Biol 1990; 37:1073-1077.

27. Reubi JC, Kvols LK, Waser B, et al. Detection of somatostatin receptors in surgical and percutaneous needle biopsy samples of carcinoids and islet cell carcinomas. Cancer Res 1990; 50:59695977.

28. Reubi JC, Modigliani E, Calmettes $\mathrm{C}$, et al. In vitro and in vivo identification of somatostatin receptors in medullary thyroid carcinomas, pheochromocytomas and paragangliomas. In: Calmettes C, Guliana JM, eds. Medullary Thyroid Carcinomas. London: John Libbey Eurotext Ltd.; 1989: Vol 211:85.

29. Warren WH, Lee I, Gould VE, et al. Paragangliomas of the head and neck:ultrastructural and immmunohistochemical analysis. Ultrastruct Pathol 1985; 8:333-343.

30. Hamid QA, Bishop AE, Rode J, et al. Duodenal gangliocytic paragangliomas: a study of 10 cases with immunocytochemical neuroendocrine markers. Hum Pathol 1986; 17:1151-1157.
31. Lundberg JM, Hamberger B, Schultzberg M, et al. Enkephalinand somatostatin-like immuno-reactivities in human adrenal medulla and pheochromocytoma. Proc Natl Acad Sci U S A 1979; 76 : 4079-4083.

32. Reubi JC, Chayvialle JA, Franc B, et al. Somatostatin receptors and somatostatin content in medullary thyroid carcinomas. Lab Invest 1991; 64:567-573.

33. McKinney M, Barrett RW. Biochemical evidence for somatostatin receptors in murine neuroblastoma clone N1E-115. Eur J Pharmarcol 1989; 162:397-405.

34. Reubi JC, Cortes R, Maurer R, et al. Distribution of somatostatin receptors in the human brain: an autoradiographic study. Neuroscience 1986; 18:329-346.

35. Reubi JC, Lang W, Maurer R, et al. Distribution and biochemical characterization of somatostatin receptors in tumors of the human central nervous system. Cancer Res 1987; 47:5758-5764.

36. Reubi JC, Maurer R, von Werder K, et al. Somatostatin receptors in human endocrine tumors. Cancer Res 1987; 47:551-558.

37. Reubi JC, Maurer R, Klijn JGM, et al. High incidence of somatostatin receptors in human meningiomas: biochemical characterization. J Clin Endocrinol Metab 1986; 63:433-438.

38. Reubi JC, Horisberger U, Lang W, et al. Coincidence of EGF receptors and somatostatin receptors in meningiomas but inverse, differentiation-dependent relationship in glial tumors. Am J Pathol 1989; 134:337-344.

39. Reubi JC, Waser B, Foekens JA, et al. Somatostatin receptor incidence and distribution in breast cancer using receptor autoradiography: relationship to EGF receptor. Int J Cancer 1992; 46:416420.

40. Fekete M, Wittliff JL, Schally AV. Characteristics and distribution of receptor for [D-Trp ${ }^{6}$-luteinizing-hormone-releasing hormone, somatostatin, epidermal growth factor and sex steroids in 500 biopsy samples of human breast cancer. J Clin Lab Anal 1989; 3: 137-141.

41. Papotti M, Macri L, Bussolati G, Reubi JC. Correlative study on neuro-endocrine differentiation and presence of somatostatin receptors in breast carcinomas. Int J Cancer 1989; 43:365-369.

42. Reubi JC, Waser B, Sheppard M, Macaulay V. Somatostatin receptors are present in small-cell but not in non-small-cell primary lung carcinomas. Int J Cancer 1990; 45:269-274.

43. Sagman U, Mullen JB, Kovacs K, et al. Identification of somatostatin receptors in human small cell lung carcinoma. Cancer 1990; 66:2129-2133.

44. Reubi JC. Somatostatin receptor subtypes in human tumors. Metabolism 1992; $41: 13$ (abstract).

45. Bell GI, Riesine T. Molecular biology of somatostatin receptors. Trends Neurosci 1993; 16:34-38.

46. Yamada Y, Kagimoto S, Kubota A, et al. Cloning, functional expression and pharmacological characterization of a fourth (HSSTR4)) and a fifth (HSSTR5) human somatostatin subtype. Biochem Biophys Res Commun 1993; 195:844-852.

47. Bruno JF, Berelowitz M. Somatostatin receptors: orphan that found family and function. Mol Cell Neurosci 1993; 4:307-309.

48. Rohrer L, Raulf F, Bruns C, et al. Cloning and characterization of a fourth somatostatin receptor. Proc Natl Acad Sci U S A 1993; 90 : 4196-4200.

49. Eriksson B, Skogseid B, Lundqvist G, et al. Medical treatment and long-term survival in a prospective study of 84 patients with endocrine pancreatic tumours. Cancer 1990; 65:1883-1891.

50. Bakker WH, Krenning EP, Reubi JC, et al. In vivo application of [ ${ }^{111}$ In-DTPA-D-Phe ${ }^{1}$ ]-octreotide for detection of somatostatin receptor-positive tumors in rats. Life Sci 1991; 49:1593-1601. 